\title{
Synthesis of CdTe Quantum Dots in Sol-gel-Derived Composite Silica Spheres Coated with Calix[4]arene as Luminescent Probe for the Pesticides
}

Haibing Li*and Fengge Qu

Key Laboratory of Pesticide and Chemical Biology (CCNU), Ministry of Education, College of Chemistry, Central China Normal University, Wuhan 430079, PR China

Supporting Information

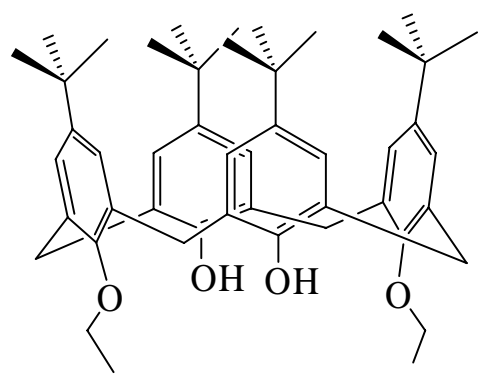

Figure S1. The structure of C[4] 

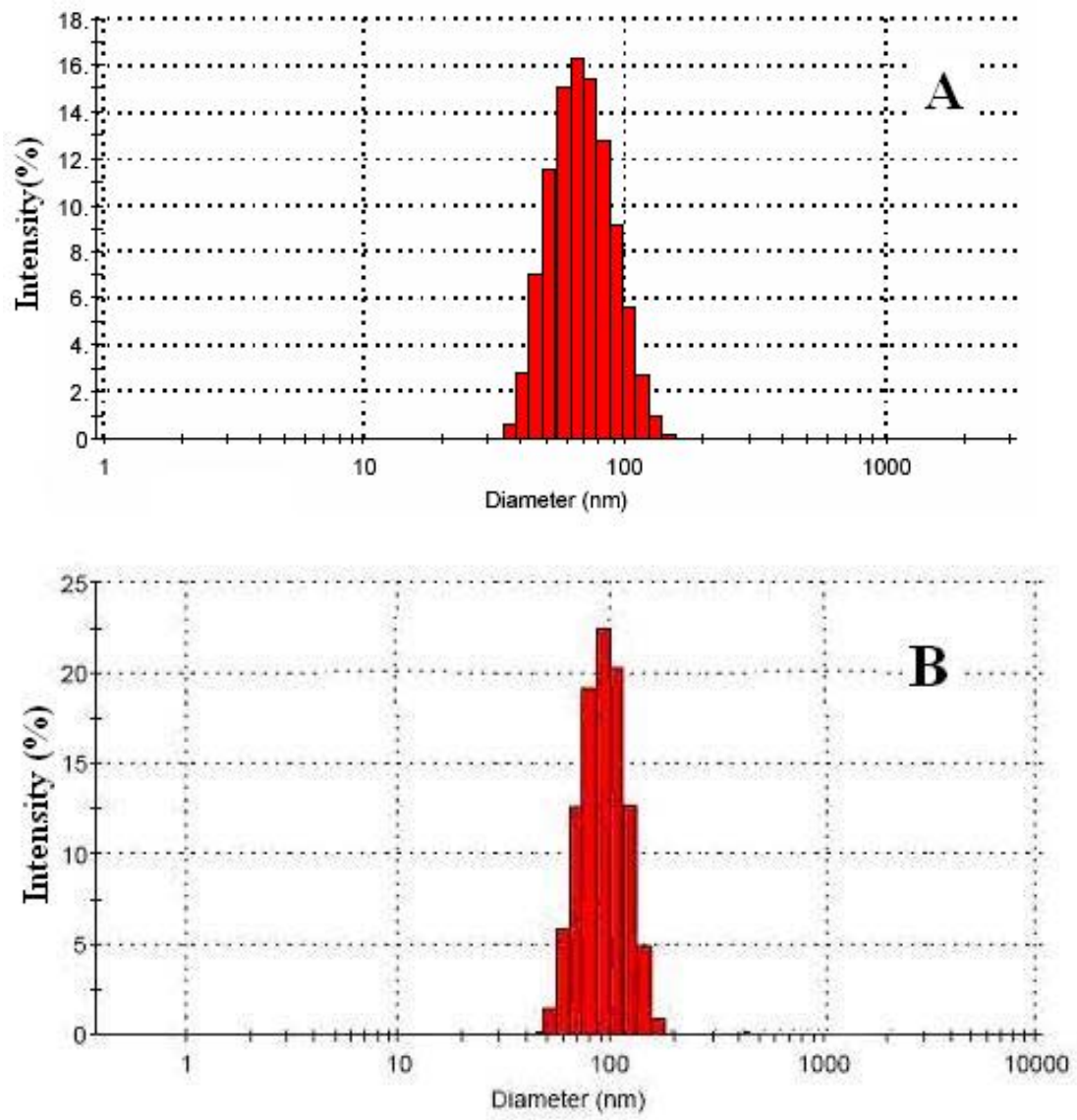

Figure S2. The size distribution of (A) $\mathrm{SiO}_{2} / \mathrm{CdTe} N \mathrm{NP}$ and (B) $\mathrm{C}[4] / \mathrm{SiO}_{2} / \mathrm{CdTe}$ NPs. 

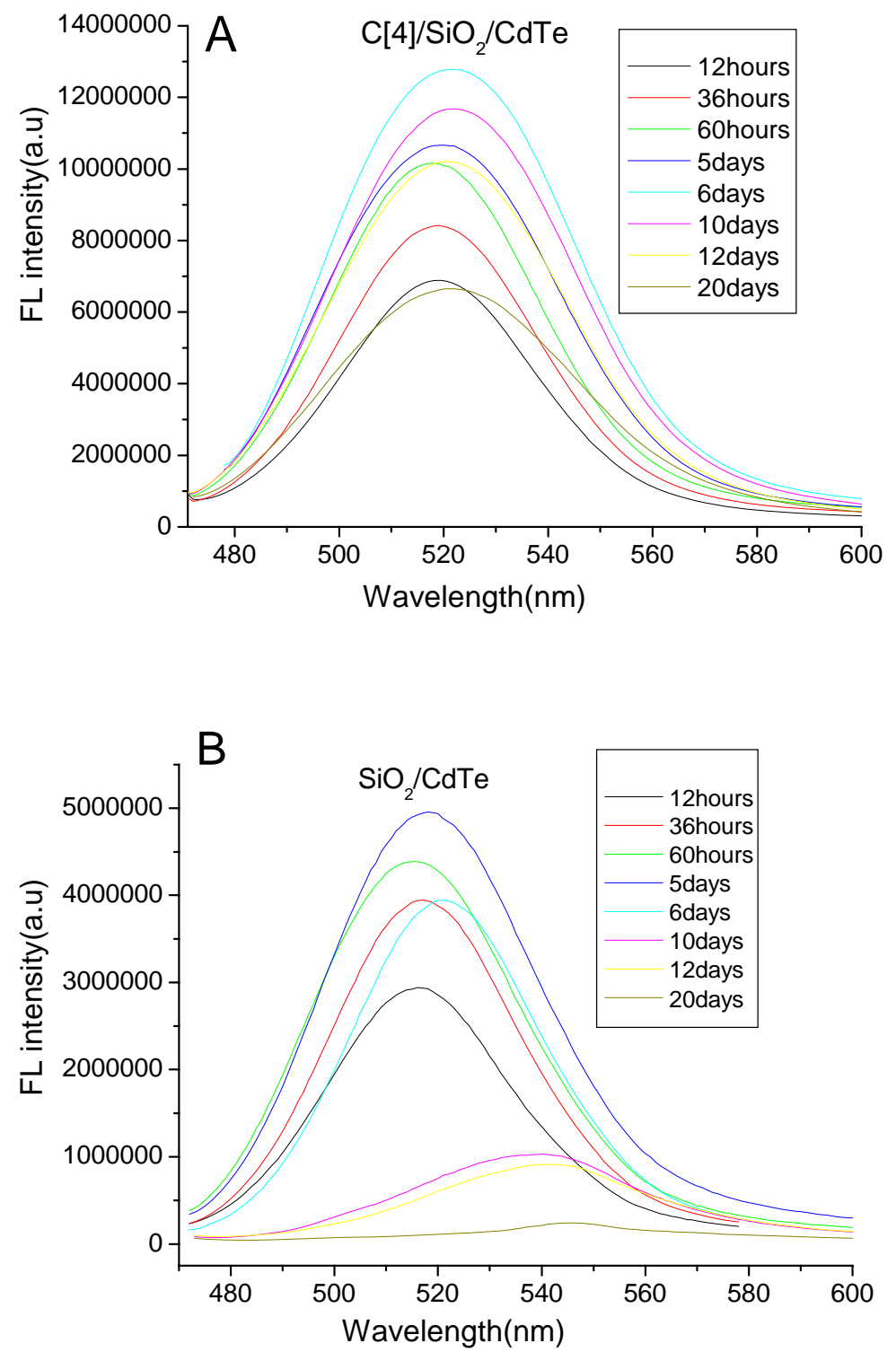

Figure S3. The photostability of $\mathrm{SiO}_{2} / \mathrm{CdTe} \mathrm{NPs}$ and $\mathrm{C}[4] / \mathrm{SiO}_{2} / \mathrm{CdTe} \mathrm{NPs}$. 


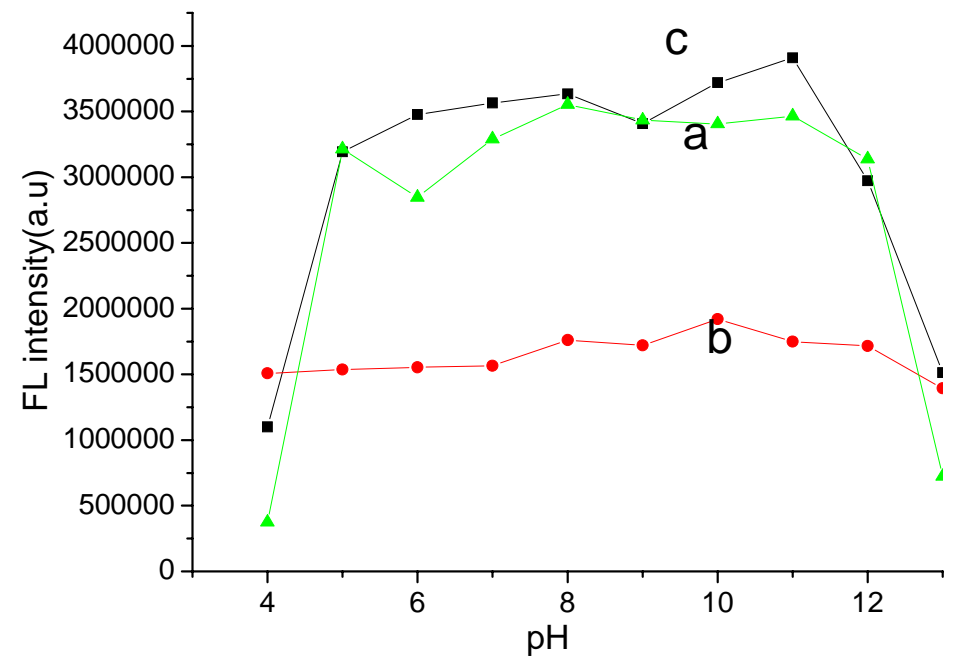

Figure S4. Effect of $\mathrm{pH}$ on luminescence response of (a)CdTe QDs, (b) $\mathrm{SiO}_{2} / \mathrm{CdTe}$

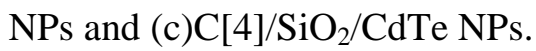

